\title{
Serviço Doméstico: elementos políticos de um campo desprovido de ilusões ${ }^{1}$
}

Jurema Brites Apresentarei aqui algumas reflexões extraídas de uma pesquisa etnográfica sobre serviço doméstico realizada entre os anos de 1995 e 1998, no Espírito Santo. Nesta pesquisa me defrontei com um paradoxo entre a leitura que os estudiosos do serviço doméstico faziam desta ocupação e a opinião das mulheres trabalhadoras que fizeram parte de minha amostra.

Enquanto a bibliografia denunciava que os patrões submetiam as empregadas a um sistema de dominação perverso através das relações clientelistas, eu encontrava no meu trabalho de campo evidências cada vez mais abundantes do quanto elas, pelo menos as empregadas domésticas de J ardim Veneza ${ }^{2}$, valorizavam este tipo de relacionamento. Nenhuma atitude das patroas poderia ser mais revoltante do que a "mesquinharia". Não passar as roupas usadas das crianças para os filhos da empregada, deixar de presenteá-la com um sofá velho, renegar sobras de comida, ou reclamar do sumiço de sabonete - todos esses "presentes", que os analistas arrolam como o "aviltante pagamento extra-salarial", faziam, aos olhos das empregadas, a diferença entre uma "boa patroa" e uma que era insuportavelmente avarenta.

O serviço doméstico não pode ser considerado exatamente uma ocupação preferida no espectro de escolhas profissionais das trabalhadoras. Entretanto, quando outras opções de inserção no mercado de trabalho se mostram inatingíveis, o serviço doméstico aparece como um trabalho com possibilidades inexistentes no mercado de trabalho formal. Vantagens de negociar adiantamentos, faltas, horários e as ajudas materiais advinda da casa dos patrões foram apontadas como "o que vale a pena" no serviço doméstico.

Campos 3:65-82, 2003. O problema que minha pesquisa de campo introduziu nesta discussão é que 
as vantagens destacadas pelas empregadas domésticas por mim investigadas coincidem justamente com aqueles fatores que os pesquisadores da condição feminina consideram como as raízes da subordinação que o serviço doméstico acarreta: relações personalistas e clientelistas estruturadas na organização da família patriarcal.

Num horizonte cada vez mais marcado pelos chamados da participação política moderna, onde a democracia passa pelo reconhecimento dos direitos de cada um, como encarar essas atitudes sem condená-las ao anacronismo político? Meu dilema era decidir se as empregadas domésticas vivem em um universo político tão "atrasado" que são levadas a avaliar positivamente aquilo que os analistas consideram completamente negativo (ver, por exemplo, Farias 1983; Godsmith 1993; León 1993; Motta 1977), ou se os relacionamentos clientelistas com os patrões são, de fato, táticas que lhes possibilitam tirar o melhor proveito possível de uma situação altamente desfavorável ${ }^{3}$.

Para tentar responder a essa pergunta, fiz um longo percurso, cheio de percalços. Foi durante o processo da pesquisa que fui me dando conta da natureza inadequada de uma série de conceitos girando em torno da noção de cidadania - conceitos que, até aquele momento, pareciam-me pertinentes. Vi que as críticas usuais dirigidas às práticas "clientelistas" não esclareciam muito daquilo que queria entender, mas se constituiam num ponto de partida para a construção de meu objeto. Passei também pela noção de bilingüismo à Bakhtin que parecia dar melhor conta da dinâmica semi-autônoma da cultura popular que eu pretendia retratar. Mas de novo, aos poucos, fui ficando insatisfeita com o que parecia cada vez mais uma análise que não levava em conta, de forma adequada, a questão da desigualdade política. Foi passando por essas tentativas e erros que cheguei em teóricos tais como S. Colen, E.P. Thompson e J. Scott.

\section{DO CLIENTELISMO À REPRODUÇÃO ESTRATIFICADA}

Um dos traços apontados como característicos da cultura política brasileira, não apenas dos grupos populares, tem sido - nas análises tradicionais - o clientelismo (Nunes Leal 1975; Lanna 1995). O clientelismo tem sido interpretado como a expressão mais acabada de uma herança tradicional, quase que fora de lugar, não fossem as evidências cotidianas destas práticas em nosso país, que levam muitos a considerar que na sociedade brasileira fazemos conviver um mundo "arcaico" com um mundo "moderno".

Cabe lembrar que o clientelismo é um conceito usado já na sociedade romana antiga, para descrever relações assimétricas entre patrícios e plebeus num contexto onde a família patriarcal desempenhava funções que ultrapassavam as do Estado. Esse conceito foi recuperado e tomou força na sociologia americana das décadas de 60 e 70, quando muitos intelectuais se envolveram com projetos "desenvolvimentistas" para o Terceiro Mundo. 
Com o olhar profundamente marcado pela noção de modernidade que traziam de seu próprio mundo, estes cientistas sociais criaram dicotomias para explicar o "atraso" de determinadas sociedades em relação à "modernidade", por exemplo, da América do Norte. As relações personalistas aqui observadas eram relacionadas a uma carência de formalizações institucionais, as quais um Estado moderno deveria desenvolver (Leeds 1977; Foster 1961).

Pretendia-se expor uma situação política não reconhecida nos países anglo-saxãos, onde as articulações políticas são supostamente elaboradas a partir de coletividades e não a partir de arranjos pessoalizados. Entre as características da política baseada na coletividade está a suposição de uma organização impessoal, onde cada um dos indivíduos envolvidos será beneficiado de maneira similar a todos os outros. O outro modelo ("arcaico") pressupõe um sistema de trocas assimétricas e estruturadas a partir de relações pessoais ou "relações diádicas" (Lande 1977).

O trabalho de Shellee Colen, embora não trate diretamente do problema do clientelismo, traz uma desmistificação primorosa dos princípios mais etnocêntricos dessa teoria. A partir de seu estudo sobre empregadas domésticas caribenhas e seus patrões americanos no coração do Primeiro Mundo (Nova lorque), Colen mostra que as relações clientelistas funcionam para ambas partes. As caribenhas são preferidas exatamente porque (ao contrário de mulheres pobres nascidas nos Estados Unidos) aceitam as longas horas de trabalho, o afastamento de suas próprias famílias, e mantêm relações carinhosas com as crianças cobradas pelas patroas. Estas, por sua vez, são mulheres americanas de alto poder aquisitivo que não poderiam ter carreiras de tanto êxito se não contassem com estas babás. Avalizando os benefícios e os prejuízos destes contratos está a possibilidade colocada (muitas vezes ratificada) destes patrões tornarem-se patrocinadores do green card para suas babás. Estes acordos têm sido tão comuns que a autora sinaliza que o emprego de babá tem sido incluído entre as primeiras estratégias para migrantes latinas nos Estados Unidos. Pela noção de reprodução estratificada, Colen mostra como relações clientelistas se inserem perfeitamente no sistema mundial contemporâneo, reproduzindo desigualdades em termos de gênero, raça e em uma dimensão transnacional.

Na verdade, a visão binária que separa atitudes arcaicas de atitudes modernas de participação política tem sido bastante desconstruída pelos críticos da world system theory (ver Sahlins 1992, e, para uma discussão centrada no Brasil, Lanna 1995). Estes, tal como Colen, procuram se afastar de modelos interpretativos generalizantes, calcados na realidade dos paises centrais. Destacam a importância dos estudos locais não apenas para o reconhecimento da diversidade, mas também para que esses novos dados sirvam para repensar os preceitos analíticos utilizados para estudar as relações de poder entre as sociedades.

Citemos o exemplo de Geert Banck (1999), antropólogo holandês com longa experiência no Espírito Santo. 
J urema Brites

Este pesquisador estuda as raízes do clientelismo no Brasil, sugerindo que as análises clássicas voltadas para este tema têm trazido certa imprecisão, pois misturam dois campos de ação e representação distintos: um é aquele que se refere às relações interpessoais e outro é o da relação entre políticos e seus eleitores. Segundo Banck, no Brasil estes campos nem sempre se misturam, sendo comum a desconfiança popular com tudo que se denomina "político", contrastando com a confiança que se deposita nas relações clientelistas que envolvem parentes, vizinhos e patrões.

Fruto da combinação de paradigmas da Ciência Política e da Antropologia, esse conceito, para o antropólogo, acaba por se auto-desqualificar quando, no lugar de explicar, simplesmente imputa às práticas denominadas "clientelistas" o adjetivo de "arcaicas" e "provincianas" (Banck 1999: 104). O que se depreende dessas análises é uma suposição de que estas práticas se gestaram no contexto rural e que ao serem transpostas para o mundo urbano condenam essas sociedades à estagnação. Banck argumenta que "práticas clientelistas" não estiveram confinadas a áreas rurais no passado; antes, eram comuns na elite comercial exportadora do Brasil imperial. Rediscutindo esses conceitos e as relações que ele supõe, Banck considera que

“o processo político brasileiro era e é muito dinâmico, e atualmente trata-se de uma bem elaborada democracia de massa. Se existem dilemas, arraigados no seu passado ou na sua cultura política, esta última não deveria ser vista como uma tábula rasa para a incapacidade estática, mas antes como um repertório cultural para a mudança" (Banck 1999: 107)4.

A partir desta perspectiva parece-me importante manter uma postura crítica ante as categorias elencadas nas representações das empregadas domésticas, procurando reconhecer nas categorias êmicas um sentido propositivo e não um anacronismo político.

\section{DO BILINGÜISMO A UM CAMPO DE FORÇAS “DESPROVIDO DE TODA ILUSÃO”}

Outro ponto de interrogação destacado nesta investigação relaciona-se ao trabalho de Pierre Bourdieu. Verificamos certas tentativas de aproximações ao estilo de vida dos patrões, especialmente em famílias de empregadas domésticas ascendentes. Poderíamos ter sublinhado a imitação de códigos culturais dos patrões por parte das empregadas, como um processo de reprodução da cultura dominante. Porém, comparando as práticas cotidianas de organização do espaço doméstico na casa de patroas e na casa de empregadas (os circuitos de ajuda mútua, as relações de gênero, e até a decoração das casas), ficava evidente que as influências da cultura dos grupos populares 
não deviam ser subestimadas 5 . Parecia existir uma margem grande de operação com códigos culturais próprios dos grupos populares; não de forma autônoma, mas também não totalmente subjugada aos padrões dominantes.

Procurando, por assim dizer, marcar uma distinção entre nossa linha de investigação e a de Bourdieu, consideramos, durante algum tempo, o conceito de bilingüismo de Bakhtin (1987) um bom caminho para descrever o comportamento, as atividades e as elaborações das empregadas domésticas na sociedade brasileira atual. Estudando a interação entre a nobreza e os plebeus na Idade Média e no Renascimento, o autor propõe que a nobreza, naquela época, era bilingüe. Referia-se à maestria com que os nobres lidavam com a tradição da cultura popular, o que Ihe possibilitava não apenas uma interpretação de seu linguajar, ritos e manifestações, como permitia trocas e comunicabilidade entre esses estratos da sociedade, num relacionamento mais estreito do que se verifica hoje, entre a elite e os grupos populares.

Pelas características que o serviço doméstico tomou na sociedade urbana atual, pensávamos que, de uma certa forma, as empregadas domésticas é que mantinham essa característica de bilingüismo. Elas transitam em mundos bastante diferentes - aquele de seu cotidiano doméstico e o de seus patrões. Diariamente entram nos lares da classe média e alta e, pela natureza do trabalho que executam, acabam conhecendo os detalhes mais íntimos dessas famílias. Passam os dias inteiros de trabalho assistindo, convivendo e participando de um mundo onde os valores e a organização doméstica são diferentes daqueles de onde elas provêm. Em suma, os empregados, sobretudo aqueles que trabalham no mundo doméstico, conhecem o modo de vida dos patrões. Os patrões, pelo seu turno, no mundo urbano moderno, afastaram-se muito dos seus empregados. Se bem que padrões de paternalismo, característico do mundo rural, persistam em muitos setores da vida nas cidades, efetivamente 0 contato entre as classes mudou 6 . Patrões hoje podem escutar os relatos dos trabalhadores sobre seu cotidiano, entretanto não conhecem pessoalmente suas casas, não sabem quem compõe sua unidade doméstica e não tomam mais seus filhos como afilhados ${ }^{7}$. Portanto, nosso raciocínio era de que, ao avesso do contexto da Idade Média, aqui quem estaria tendo maiores chances de navegar por estes dois mundos, era a "plebe" e não a "nobreza". Através do trânsito entre as práticas e os valores que vivenciavam entre seu universo cultural e o dos patrões, parecia-nos que empregadas domésticas eram capazes de decifrar códigos diferentes de relações de trabalho, de organização familiar, de concepções de organização e limpeza.

Aos poucos, no entanto, o conceito de bilingüismo foi mostrando-se inadequado. Em primeiro lugar, porque existiam espaços nos quais as empregadas domésticas manifestamente não dominavam os códigos. Por exemplo, nenhuma empregada que estudei saberia passar despercebida se fosse assistir a uma peça no teatro municipal, ou se decidisse simplesmente jantar num bom hotel. Sua habilidade em lidar com algumas regras no espaço doméstico das classes dominantes não fazia dela uma pessoa "bilingüe" nesse sentido. 
Em segundo lugar, apesar de ressaltar a diversidade cultural, o conceito de bilingüismo não leva em conta a profunda desigualdade que rege as relações entre as classes. Neste sentido, Thompson (1979) parecia fornecer uma saída. Na sua descrição das relações paternalistas que se estabeleciam entre a "gentry" e os "plebeus" ingleses no século XVIII, Thompson chama atenção para um processo muito semelhante ao que nós observamos hoje na sociedade brasileira. Mostra as estruturas definidas pela hegemonia da gentry, mas completa colocando em questão o que a hegemonia não pressupõe:

"A hegemonia não acarreta que os pobres aceitem o paternalismo da gentry nos próprios termos da gentry ou segundo sua auto-imagem consagrada. Os pobres podiam se dispor a conceder sua deferência à gentry, mas apenas por um preço, que era substancial. E a deferência era freqüentemente desprovida de qualquer ilusão: a partir de baixo, podia ser vista em parte como auto-preservação necessária, em parte com extração calculada do que podia ser conseguido. Visto dessa maneira, os pobres impunham aos ricos alguns dos deveres e funções do paternalismo, assim como a deferência lhes era por sua vez imposta. Ambos os lados estavam aprisionados num campo de força comum" (1998:78).

O jogo embutido nas relações paternalistas, típica das relações entre empregadas domésticas e seus patrões em nossa sociedade é um exemplo onde podemos encontrar trocas semelhantes a estas descritas por Thompson. Claro que não é possível desconsiderar que as estruturas que ordenam a contratação/ prestação desses serviços são marcadas fortemente pelos grupos dominantes que estabelecem preços do serviço doméstico e exigem atitudes servis de seus empregados, demarcando sempre relações hierárquicas. Por seu lado, é importante remarcar que as empregadas retiram desse sistema muito mais do que legitimamente ele oferece. Materialmente desfrutam do trânsito de patrimônio, seja através dos presentes recebidos, seja através dos furtos, lançando mão do mesmo referencial ideológico dos patrões: retiram o melhor proveito da situação. Em troca devolvem-lhes servilidade, prestígio e amizade, completando o círculo de dádiva-dom. Trata-se de uma troca social, como diz Thompson, "desprovida de ilusões", onde ambos lados estavam obrigados a se mover num "mesmo campo de forças".

\section{DOS ROTEIROS ENCOBERTOS À CIDADANIA CONTEXTUALIZADA}

Os ritos de interelação entre gentry e plebeu descritos por Thompson assemelham-se aos roteiros públicos (public transcript), conceito cunhado por J . Scott. O interesse neste último teórico, além de ter trazido noções de Thompson para o estudo etnográfico de acontecimentos contemporâneos, encontra-se principalmente na sua insistência em combater noções simplistas de hegemonia. Como Thompson, Scott afirma que, atrás dos comportamentos 
formas de interação aberta entre os subordinados e aqueles que os dominam, os roteiros públicos, revelam apenas uma parte da relação:

“O roteiro público (public transcript), quando não é positivamente enganador, tende a esconder muita coisa das relações de poder. É freqüentemente do interesse de ambas partes colaborar tacitamente para promover essa 'má representação'" (misrepresentation). (Scott 1990:2)

Como contraponto, Scott sugere a observação do comportamento prescrito, os roteiros encobertos, que se desenrolam atrás dos bastidores:

"Aqui estou pensando nas armas banais dos grupos com relativamente pouco poder: a lentidão proposital, a dissimulação, a deserção, a falsa deferência, o roubo de pequenos objetos, o 'fazer-se de besta', a calúnia, o incêndio, a sabotagem, etc."(Scott 1985: xvi)

A abordagem de Scott pressupõe que, "atrás dos bastidores", quando subalternos deixam de seguir as regras do roteiro público, expressam atitudes bem menos reverentes em relação a seus superiores. Se, na grande maioria das vezes, os mais fracos não usam o enfrentamento direto ou práticas organizadas de reação à dominação, não é por concordarem passivamente com o sistema. É, pelo contrário, justamente porque tais estratégias seriam relativamente ineficazes, senão inúteis ou até suicidas. A maneira dos subalternos agirem sabiamente, minimizando seus prejuízos, é operando nas brechas, usando astúcia para burlar, antes do que derrubar, o sistema.

Trata-se de uma forma de participação política que, na maior parte da literatura, é colocada como oposta à cidadania. Nos últimos anos, porém, alguns antropólogos têm repensado esse tipo de dicotomia, propondo, que no seu lugar, pensemos na contextualização da própria noção de cidadania.

Estes pesquisadores têm se dedicado a refletir sobre setores da sociedade brasileira onde se valorizam relações menos marcadas pelo ideário moderno, isto é, onde o valor básico promulgado não é necessariamente o da igualdade de direitos. No lugar de propor uma integração dos subalternos aos modelos dominantes, ou tomar essas "resistências" como conservadorismo ou ignorância política, eles têm procurado reconhecer no "ponto de vista nativo" críticas a um projeto monolítico de modernização política.

Segato (1995) descrevendo as características e ações dos Orixás que compõem o panteon afro-brasileiro, assim como as simpatias dos adeptos pelos seus deuses, indica uma leitura crítica dos padrões de poder de nossa sociedade. Mostra que os adeptos do Xangô do Recife elegem como os prediletos de sua devoção Xangô e Oxum. Ambos Orixás são donos de personalidades e atitudes muito especiais. Xangô é o Orixá mais malicioso e oportunista do panteon, lançando mão de estratégias astutas para conseguir da maneira mais fácil, aquilo que deseja. Oxum, por sua vez, corresponde à feminilidade frívola, acostumada ao luxo e ao conforto, mas que 
afetivamente é muito condescendente com seus filhos. Contrastando com a simpatia que sente por estas entidades, o povo de santo nutre desconfiança ante o poder legítimo que lemanjá - a rainha-mãe - possui. lemanjá é considerada fria e falsa. Defende seus protegidos, passando por cima da lei e, para esquivar-se dos ataques ao seu poder, semeia a intriga entre seus oponentes. A Oxalá, pai de todo o panteon, os fiéis reservam respeito, mas o vêem como um velho que não é mais dono de seu poder. Em outras palavras, o casal fundador do panteon - os quais representam o poder instituído - não é muito apreciado entre os filhos de santo. Descrevendo assim as representações acerca dos Orixás, Segato aponta para uma visão muito sagaz que esta população desenvolve, tanto sobre a política nacional, quanto sobre a posição que eles detêm neste mundo.

Nessa mesma linha de investigação, Regina Novaes (1995), discordando da apreciação que se difundiu a respeito do "conservadorismo" das religiões pentecostais, mostra como estas incorporam elementos simbólicos muito próximos ao ideário moderno de igualdade. Ao promoverem uma "separação entre as coisas do mundo" e as de Deus, os pentecostais constróem uma proposta de vida, um modelo que dignifica a vida do pobre. As práticas políticas dos grupos pentencostais, sugere a autora, antes de representarem alienação diante das coisas do mundo, pautam-se numa produção de sentido que prioriza a dimensão religiosa da realidade. Entre eles, a experiência política é encompassada pela religiosidade. Assim os seus posicionamentos políticos respeitam os princípios consonantes com as demais representações do grupo, cujo comprometimento com a fé se sobrepõe a uma inserção racionalista na vida. Neste movimento, acabam por sacralizar a política. Em contraste com este tipo de inserção política, Novaes mostra como a proposta do modelo de ação da CEBs - Comunidades Eclesiais de Base, que representa a experiência de polarização das alas progressistas da Igreja Católica - é de politizar a religião, trazendo a "lucidez moderna" aos homens de fé.

No âmbito da religião, estes estudos apontam para o questionamento do sentido de "politização" que tem constituído a definição de cidadania, indicando que muitas perspectivas populares são rejeitadas enquanto expressão do campo político.

Corroborando estas preocupações, Carvalho (1987), ao estudar a participação popular no advento da República, desvenda um ideário libertário da elite que não era partilhado pela população em geral. As manifestações populares, em contrapartida, eram desconsideradas na construção da "democracia". Os valores políticos muito afastados das representações populares, que se estabeleceram com a República, eram, para o historiador, uma imposição das elites. Assim ele propõe que, em vez de surgir uma democracia - enquanto espaço público de participação cidadã - fora construído uma "estadania".

Estes autores vêm chamando atenção para o fato de que, como disse Otávio Velho, “até hoje, as elites [no seu apego à modernização] não têm sido capazes de criar um imaginário que empolgue a população" (1995: 160). 
Estas análises procuram ver nas formulações dos grupos populares - nas suas variadas expressões - algo mais do que resistência ou comportamento arcaico. Busca-se apreender questionamentos sobre a legitimidade das representações hegemônicas sobre ordem e poder.

Luís Fernando Duarte insiste na necessidade de contextualizar o ideário liberal-individualista, se quisermos refletir sobre as possibilidades e limites da integração das classes populares no processo de "cidadanização". J untamente com estes outros autores, ele aponta não apenas para a incapacidade do discurso oficial e hegemônico de representar/incluir as "diferenças" (até mesmo porque, segundo Duarte, faz parte deste ideário "da cultura ocidental a conversão do 'outro'"), mas para a possibilidade deste "outro" ter o quê dizer sobre o processo da modernização (Duarte 1993: 17)

\section{O SISTEMA DE AÇÃO}

Para terminar, optamos por mais uma vez voltar aos dados concretos de campo, procurando entender como funcionam, nas atuais circunstâncias, as políticas que pretendem tirar a empregada doméstica das suas relações clientelistas e colocá-la dentro do mundo professional moderno.

As perspectivas "modernas" de participação política repercutem nas relações de trabalho entre patrões e empregados, na atitude, cada vez mais difundida entre os patrões, de que um compromisso contratual, respeitando os princípios legais, define relações mais justas. Muitos patrões bem intencionados (da minha amostra) consideram que, como cumprem devidamente a legislação trabalhista (embora no caso do serviço doméstico ela ainda seja muito precária), estão fazendo sua parte para uma sociedade melhor. E quando suas "funcionárias" não respondem às regras do contrato, relegam seu comportamento ao atavismo, falta de predisposição ao trabalho ou desonestidade. É importante observar que em certa medida o código contratualista exime os patrões de um comprometimento com as diferenças sociais, pois ele retira a desigualdade e a justiça do campo da moral. A igualdade passa a ser prescrita por um contrato.

A questão é: será que as empregadas reconhecem as vantagens dessa nova forma de relação? A experiência de uma empregada no seu embate com o patrão acerca dos direitos trabalhistas pode dar certas indicações do contrário.

Emengarda havia sido demitida (sem justa causa) depois de ter faltado dois dias ao trabalho em função de uma infecção renal. Primeiramente, apelou para a cordialidade dos patrões, inclusive apresentando atestado médico, que os patrões consideraram falso. Depois acabou sugerindo que nem todos seus direitos haviam sido pagos 
J urema Brites

(aviso prévio, décimo terceiro salário etc.), mas acenando com possibilidade de algum acerto. Porém, como eles mantiveram-se irredutíveis, procurou o Sindicato dos Trabalhadores Domésticos. O patrão dela compareceu então ao sindicato com uma série de notas fiscais de produtos comprados em seu nome (rádio, fogareiro, relógio), dizendo que estes itens encontravam-se na casa de Emengarda - prova que ela os havia furtado dele. Como eu tinha acesso tanto à casa dos patrões, como à da empregada, sabia que estes não eram itens roubados por Emengarda. Ela apenas usou - como é de praxe nas relações locais - o nome de seus patrões para abrir um crediário, cujas prestações pagou sozinha.

É interessante que seu Péricles, o patrão, não foi à policia para reaver as coisas que, afinal, legalmente lhe pertenciam. Nesta falsa acusação o patrão utilizou-se de prerrogativas de classe para obstruir um processo jurídico. Em função de sua condição econômica ele auxiliou, com os artifícios das relações clientelistas, o acesso da empregada aos bens de consumo. Quando as expectativas desse acordo foram frustradas, ele recorreu aos métodos de pressão (pouco idôneos) proporcionados por sua posição de classe.

Emengarda nem sequer cogitou em pedir às suas vizinhas, que trabalham nas mesmas redondezas, para deporem a seu favor no sindicato. As colegas de Emengarda têm consciência que não é o confronto direto que Ihes trará vantagens nessa briga desigual. Para não comprometerem seu mercado de trabalho evitam mostrar-se passíveis de recorrer aos mesmos métodos de Emengarda, ao procurar seus direitos legais. Por outro lado, sabem que casos como este, quando chegam a desdobramentos que envolvem inquéritos jurídicos e policiais, raramente são bem sucedidos. Até mesmo pela operacionalidade dos processos que passam pelo universo da escrita (do qual estão distantes) reconhecem que facilmente podem perder o controle da situação. Sabem que seus delitos (quando existem) são muito mais facilmente flagrados pela lei, do que aqueles de seu Péricles. Assim, cientes de que não dominam plenamente o jogo dentro do aparato que na sociedade dizzelar por direitos igualitários, procuram nas relações com os patrões, condutas que julgam capazes de negociar.

Entende-se então por que, nas disputas de direitos com seus patrões, as empregadas da nossa amostra raramente procuravam a proteção do Sindicato das Empregadas Domésticas situado em Vitória. A julgar pelo número de associadas que o sindicato mantinha depois de quase uma década de atuação no Espírito Santo, elas estavam de acordo com a maioria de mulheres nesta categoria de trabalho. Em 1998, o Sindicato dos Trabalhadores Domésticos e Empregados de Edifícios do Espírito Santo contava com apenas 9 mulheres associadas.

A valorização do relacionamento pessoalizado com os patrões pôde ser observada até mesmo entre as empregadas mais comprometidas com os direitos trabalhistas, aquelas que tinham uma dedicada militância política ${ }^{10}$. As duas mulheres que durante dez anos mantiveram em pé o sindicato das domésticas de Vitória sustentam laços de amizade com seus ex-patrões até hoje. Na prática política de sindicalistas sempre buscam primeiro a via da 
conciliação, antes de um enfrentamento judicial com os patrões. E o fazem pelo profundo conhecimento que dispõem de sua categoria profissional: são mulheres pobres que não podem arcar com os custos de um processo e que não podem contar com a diligência da corte judicial. Uma das atuações mais importantes do Sindicato, aquela que a bem da verdade ainda o mantém de portas abertas, é o seu papel na homologação das rescisões contratuais. Brandt (2000) estudou o sindicato de empregadas domésticas de Campinas como espaço de construção de uma "cultura de mediação". A autora destaca que os Sindicatos têm cumprido uma função que a J ustiça do Trabalho não consegue ocupar pelo seu excesso de formalismo e generalização de situações extremamente particularizadas:

“as práticas promovidas pelo sindicato de Campinas exercem papel importantíssimo, não apenas enquanto ferramenta de regulação social desta relação de emprego, com inúmeras vantagens em relação à reclamação trabalhista, mas principalmente enquanto promotoras de novas formas de sociabilidade entre as partes ....apoiadas na idéia essencial de igualdade enquanto seres humanos. Não mais a igualdade definida pelos critérios universalizantes do direito, mas critérios locais, situacionais, construídos praticamente ao longo do processo de mediação/interação" (Brandt 2001:3).

Certamente há inúmeros e constantes abusos da "tradicional" relação paternalista da parte dos patrões. Não é nosso objetivo romantizar o clientelismo atentando apenas para exemplos mais suaves. Muitas vezes um relacionamento mais pessoalizado vem acompanhado de exigências absurdas e prerrogativas patronais exageradas. Para citar apenas um exemplo, posso descrever uma patroa que, ao desconfiar que sua empregada cometia pequenos furtos, desencadeou uma operação de investigação. Num sábado, antes que a moça partisse para seu repouso, pediu que fosse à padaria. No intervalo, ela abriu a sacola da "malandra" e constatou que ela carregava algumas coisas para casa:

"fui tirando tudo lá de dentro: olha, era modess, sabonete, até uma calcinha da Clarice... Tirei tudo da sacola dela e deixei em cima da mesa da cozinha. Chamei as meninas para esperar ela chegar. Só queria ver a cara dela. Quando ela voltou e viu que tínhamos descoberto seus roubos, ficou mais pálida que o leite!"

Não é pouco lembrar que esta patroa, ciosa da privacidade de seus pertences, não reconhecia o mesmo direito para sua empregada ao revirar-lhe a bolsa, sem pedir permissão. Nem cabe esquecer também que essa patroa não chega a pagar um salário mínimo para as moças que trabalham na sua residência - as quais só retornam para suas casas aos sábados à tarde. J ustifica que a baixa remuneração e o não cumprimento dos demais direitos trabalhistas são compensados por receberem alimentação, produtos de higiene íntima e um lugar para dormir sem pagar água, luz e aluguel. Suas empregadas "acabam ganhando mais que a gente porque no final do mês aquilo é dela, inteirinho". 
Os freqüentes e reais casos de abuso não devem ofuscar, no entanto, as vantagens que a relação paternalista é capaz de proporcionar na perspectiva destas mulheres. De maneira diferente da postura contratualista, os patrões mais claramente clientelistas, embora possam reconhecer a hierarquia como um fato natural, em geral pagam seu tributo à Nêmises.

Mostramos em outro lugar (Brites 2000) que apesar dos comentários que acusavam as empregadas de cometerem pequenos furtos, raramente os patrões levavam essas desconfianças a ponto de estabelecerem um rompimento do contrato ou de apresentarem queixas policiais. Essas reclamações, mais do que descontentamento, indicavam uma comunicação entre as partes envolvidas. Apontávamos que a tolerância de muitos patrões com os pequenos furtos cometidos ou atribuídos às domésticas poderia ser interpretado como a "vingança de Nêmisis", um princípio moral expresso no esquema de troca-dádiva proposto por Marcel Mauss, (1974). Este princípio denuncia o desequilíbrio entre a abundância de uns a e pobreza de outros. "A esmola é fruto de uma noção moral da dádiva da fortuna, por um lado, e de uma noção de sacrifício, por outro ... a Nêmisis vinga os pobres e os deuses do excesso de felicidade de certos homens, que devem desfazer-se dela" (Mauss 1974: 66).

Assim, mesmo de maneira paternalista, desenvolvem ações ante a desigualdade. Quando Pilar, uma de nossas informantes, paga o tratamento de sua ex-empregada com pneumonia ou sustenta a creche para a filha da empregada atual, mais que o cálculo do retorno da dádiva acumulada neste comportamento, expõe um reconhecimento de que não basta transferir a responsabilidade social para o pagamento de impostos. Afinal, Pilar sabe que, no atual contexto da sociedade brasileira (e, talvez em especial, de Espírito Santo), essas mulheres não têm outras instâncias para lhes abrigar.

Patrões bilingües, como Pilar, parecem, em todo caso, cada vez mais raros. No lugar da troca personalística, do discurso assimétrico do paternalismo, hoje se coloca com mais legitimidade a perspectiva igualitária da cidadania. Nesta perspectiva, a expectativa dos patrões é de encontrarem na empregada não uma amiga leal, mas uma profissional. Desta profissional esperam que cumpra suas funções remuneradas, como a lei estabelece. Mas não questionam que leis são essas, como se determina a remuneração do serviço doméstico, nem esperam que as empregadas desfrutem dos mesmos direitos de igualdade que os patrões. Uma cidadã no cumprimento da legislação, mas com status diferenciado.

Diante dessas constatações, talvez as empregadas mantenham-se desconfiadas quanto às benesses do regime contratual e busquem outras possibilidades de negociação. Sem negligenciar as promessas implícitas vindas dos superiores, observei uma tendência entre as empregadas pesquisadas de não aceitar empregos que pagassem menos de um salário e os vales-transporte. Carteira assinada, pagamento da Previdência já poderiam 
ser negociados. Mas o contrato ideal é aquele que, respeitando a legislação, vem aliado a patroas (tais como Pilar) que não são avarentas nem mesquinhas e que, portanto, continuam a garantir aquelas "dádivas" que, embora não constem do contrato, são absolutamente essenciais.

Vitória talvez não seja "típica" do Brasil. Sobretudo nos grandes centros do país (Porto Alegre, Rio de J aneiro eSão Paulo) a perspectiva patronal de propor um contrato formal de serviço tem crescido. Nestas regiões mais de $90 \%$ das domésticas possuem carteira de trabalho e ganham pelo menos um salário mínimo. Mas também existem dados destoantes dessa modernização contratual. Nos levantamentos estatísticos sobre a economia informal no Brasil, 74\% das empregadas domésticas não têm carteira assinada e se tomadas todas as mulheres (domésticas ou não) envolvidas no setor informal 66,2\% não demonstram sequer interesse em estabelecer vínculos empregatícios neste plano formal (Abreu et al. 1990; Bruschini e Lombardi 1999). Parece que a lógica contratual nem sempre é atrativa para essas trabalhadoras, pois junto com a regulamentação de seu trabalho, ao lado dos poucos direitos adquiridos, os deveres são talvez mais severos.

As exigências de uma regulamentação do serviço doméstico pressupõem que do lado dos patrões e do lado das servidoras domésticas as condições para cumprimento da lei sejam idênticas. É, por exemplo, o que demonstra o Manual do Empregador, uma publicação do Centro de Informações e Defesa dos Empregadores Domésticos de Porto Alegre, que se propõe defender os direitos dos empregadores e das donas de casa, uma vez que "sempre ouvimos as pessoas falarem sobre os direitos das empregadas domésticas, porém, poucos comentam sobre os direitos daqueles que dão emprego, os patrões" (Informativo 1997)11.

Mas até que ponto essa igualdade é praticável? Por exemplo, até que ponto pode uma empregada doméstica cumprir aviso prévio de 30 dias, ou pagá-lo, quando a natureza do serviço as coloca numa relação tão direta com seus patrões? Onde deixar seus filhos enquanto cuida dos filhos de outros? Quem define as noções de bom cumprimento das tarefas domésticas estipulado implicitamente no contrato? A fraca inserção no mundo letrado possibilita que os direitos e os deveres sejam fiscalizados e cumpridos devidamente pela empregada?

Sugerimos que não são apenas essas questões pontuais que criam um mal-estar. Embutida na legislação do Estado é a própria lógica calcada numa perspectiva de direitos individuais que vai de encontro a outras razões culturais. Trata-se de uma lógica que simplesmente não leva em conta organizações diferenciadas de modo de vida, como aquelas que mostramos existir entre as famílias de J ardim Veneza, as quais implicam num código de hierarquia e reciprocidade.

Analisando o modo de vida, a lógica das relações hierárquicas embutidas não somente no serviço doméstico, mas no dia a dia das empregadas domésticas de J ardim Veneza, voltamos finalmente nossa reflexão para dois conceitos que têm servido de base das análises sobre a vida política brasileira: clientelismo e cidadania. Ponderamos 
J urema Brites

que, dependendo de como são usados, estes termos podem apresentar as duas faces da mesma moeda. Quer se assuma uma perspectiva fatalista lamentando a persistência da política clientelista tradicional, quer se proponha visões mais otimistas em que as forças de modernização prometem integrar todos num modelo globalizado de cidadania, os grupos subalternos são colocados como o problema principal - retrógrados ou alienados cujos comportamentos e atitudes têm de evoluir. Travando perspectivas analíticas que, nos roteiros escondidos dos subalternos, revelam o caráter relativamente lúcido e plenamente moderno de suas práticas, somos levados a pensar o quadro em outros termos. Somos obrigados a pensar formas de cidadania contextualizada, para garantir um espaço a partir do qual estes "outros", não inteiramente cúmplices do ideário moderno, possam participar na própria definição dos processos de participação política.

Sem levar em conta as especificidades das relações entre patrões e empregadas domésticas que procurei descrever, corremos o risco de, a partir de generalização, jogar por terra toda uma prática política destas mulheres em condição de subalternidade e, no seu lugar, colocarmos nossa perspectiva sobre o que seja poder, democracia e participação. 


\section{NOTAS}

1 Comunicação apresentada no Fórum de Pesquisa no 13, “Experiências culturais/possibilidades políticas”, da IV Reunião de Antropologia do Mercosul.

2 A pesquisa de campo antropológica foi realizada na Grande Vitória, ES. Meu trabalho de campo foi realizado em duas etapas. A primeira durante o ano de 1996, quando como bolsista da Fundação Carlos Chagas realizei entrevistas com 5 redes de patroas e empregadas. Na fase posterior, em 1998, concentrei minhas investigações em uma rede de empregadas domésticas, quando realizei pesquisa de campo clássica, passando a residir na casa de algumas empregadas domésticas, na periferia de Vitória. Por razões éticas, os nomes dos lugares e personagens estão apresentados de forma fictícia.

3 "Táticas" são aqui utilizadas no sentido atribuído por De Certeau (1994): ações ad hoc, constantemente redefinidas de acordo com o contexto, geralmente com objetivos imediatos e carentes de um planejamento, como a noção de "estratégia" pressupõe. Para De Certeau a diferença entre "tática" e "estratégia" revela universos culturais distintos. Noções semelhantes são analisadas em Hobsbawn e Scott (apud Brites 2000).

4 The Brazilian political process was and is highly dynamic, and at present it is a fully-fledged mass democracy. If there are dilemas, rooted in its own past and political culture, the latter should not be taken as a tabula rasa for static incapacity, but as a culture repertoire for change (1999:107)

5 O debate acerca da especificidade dos grupos populares brasileiros tem tomado as dimensões de gênero e família para refletir sobre a existência ou não de valores culturais próprios destes grupos (Duarte 1986; Sarti 1989, entre outros).

6 Anthony Giddens (1991) analisa as mudanças em termos do exercício da autoridade na modernidade, mostrando que a urbanização trouxe consigo um afastamento da pessoalidade das relações de poder. O poder distancia-se de algo palpável nas relações pessoais e passa para uma esfera abstrata, longe da interferência direta dos atores envolvidos nas relações de dominação. Notadamente, esse "desencaixe", para usar os termos do autor, interfere na lógica do paternalismo por dificultar as relações pessoais.

7 Fonseca e Brites (1990) analisam, no contexto gaúcho, critérios de escolha de padrinhos ao longo de gerações de trabalhadores urbanos com maior ou menor tempo de migração. Verificam que o compadrio tem mudado de um padrão vertical (segundo o qual pobres escolhiam um compadre entre seus patrões) para um padrão horizontal, pois as famílias da atualidade não desfrutam mais da mesma intimidade com membros da classe patronal.

8 the open interaction between subordinates and those who dominate. The public transcript where it is not positively misleading, is unlikely to tell the whole story about power relation. It is frequently in the interest of both parties to tacitly conspire in misrepresentation (1990:2).

9 "Here I have in mind the ordinary weapons of relatively powerless groups: foot dragging, dissimulation, esertion, false compliance, pilfering, feigned ignorance, slander, arson, sabotage, as so on" (1985: xvi).

10 Durante alguns anos o aluguel da sala, o pagamento do telefone e a remuneração das representantes sindicais eram pagos por um certo advogado. Ironicamente, enquanto este financiava as despesas do sindicato (cerca de mil e quinhentos reais mensais), também mantinha, como presidente e assessor jurídico, o sindicato patronal. Quando esta situação tornou-se insustentável e os laços foram rompidos, a associação esteve prestes a fechar.

11 Além de explicar os direitos e deveres dos patrões e das empregadas, o manual dá conselhos quase policialescos de como se precaver da moralidade e da saúde da empregada doméstica. Na sessão "Providências para Admissão de Empregada Doméstica Cuidados necessários - Documentos a serem exigidos", o autor aconselha a solicitação de atestado de bons antecedentes criminais, a verificação de referências pessoalmente, a realização de entrevista da candidata na parte externa da residência "na frente de testemunhas", a exigência de atestado de saúde (Caldieraro 1997:17-18). 
J urema Brites

\section{REFERÊNCIAS BIBLIOGRÁFICAS}

ABREU, Alice et al. 1994. “Desigualdade de Gênero e Raça. O informal no Brasil em 1990”. Estudos Feministas, número especial $/ 2^{\circ}$ sem.: $153-178$.

BAKHTIN, Mikhail. 1987. Cultura popular na Idade Média e no Renascimento: o contexto de François Rabelais. São Paulo: Hucitec.

BANCK, G. e DOIMO A. 1988. Entre a utopia e a estratégia: um estudo de caso de um movimento social urbano. Vitória: Ed. Cultural.

BANCK, Geert. 1998. Dilemas e símbolos. Estudos sobre a cultura política do Espírito Santo. Vitória: IHGES.

.1999. "Clientelism and Brazilian political process: production and consumption of a problematic concept". In Modernization, Leadership and Participation. Theoretical Issues in Development Sociology. Amsterdan: Leiden University Press.

BOURDIEU, Pierre. 1962."Le Celibataire". Estudes Rurales 5(6):32-135.

. 1983. "Gostos de Classe e Estilos de Vida". In Renato Ortiz (org.) Bourdieu. Coleção Grandes Cientistas Sociais. São Paulo: Ática.

12.

.1994. "Stratégies de Reproduction et Modes de Domination". In Actes de la Rechercehe en Science Sociales 105: 3-

BRANDT, Maria Elisa Almeida. 2000. «O conflito entre empregadores domésticos e a atuação do sindicato: os sentidos da mediação». Texto apresentado no XXIV Encontro Anual da ANPOCS.

BRITES, J urema. 2000. Afeto, Desigualdade e Rebeldia: bastidores do serviço doméstico. Tese de Doutorado. Porto Alegre: UFRGS/PPGAS.

. 1997. “Cinderela Domesticada. Um estudo sobre saberes femininos que circulam entre empregadas domésticas e seus empregadores". Porto Alegre: Relatório Final apresentado à FCC, II Programa de Incentivo e Formação em Pesquisa sobre a Mulher.

BRUSCHINI, Crisitina e LOMBARDI, Maria Rosa. 1999. “A bi-polaridade do trabalho feminino no Brasil: o emprego doméstico e as "novas" ocupações". Trabalho apresentado na ANPOCS.

CALDIERARO, Ernesto. 1997. Como Lidar com sua Empregada Doméstica (o manual do empregador em perguntas e respostas): os direitos dos empregadores e das donas de casa no contrato de trabalho doméstico. Porto Alegre: CINDEBRA. CARVALHO, J osé Murilo. 1987. Os Bestializados. O Rio de J aneiro e a República que não foi. São Paulo: Companhia das Letras.

COLEN, Shellee. 1995."Like a mother to them: stratified reproduction and West Indian Childcare workers and employers in New York". In F. Ginsburg e R. Rapp (orgs.) Conceiving the new world order: the global politics at reproduction. Berkley: University California Press.

. 1993. Solamente um poco de respeto: trabajadoras del hogar antillanas em la ciudad de Nueva York. In Elsa Chaney e Mary Garcia Castro (orgs.) Muchacha / cachifa / criada / empleada/ empregadinha / sirvienta y... más nada: trabajadoras domésticas en América Latina y Caribe. Venezuela: Ed. EPU.

DUARTE, Luiz Fernando Dias. 1986. Da vida nervosa nas classes trabalhadoras urbanas. Rio de J aneiro: J orge Zahar. DE CERTEAU, Michel. 1994. A invenção do cotidiano: artes de fazer. Petrópolis: Vozes.

.1993. "Vicissitudes e limites da conversão à cidadania nas classes populares brasileiras". Revista Brasileira de Ciências Sociais 22 (jun): 5-19. 
FARIAS, Zaíra A. 1983. Domesticidade: “Cativeiro” Feminino? Rio de J aneiro: Achiamé/CMB.

FONSECA, Claudia e BRITES, J urema. 1990. “Um atalho até Deus: Um estudo de catolicismo popular no Rio Grande do Sul”. In Religião e Sociedade n¹5 RJ / ISER: CER.

FOSTER, George. El contrato didático: un modelo para la estructura social de una aldea de campesinos mexicanos. [texto digitado]

GIDDENS, Anthony.1990. As conseqüências da modernidade. São Paulo: UNESP.

GOLDSMITH, Mary. 1993. Políticas y Programas de las Organizaciones de Trabajadoras Domésticas en México. In Elsa Chaney e Mary Garcia Castro (orgs.) Muchacha / cachifa / criada / empleada/ empregadinha / sirvienta y... más nada: trabajadoras domésticas en América Latina y Caribe. Venezuela: Ed. EPU.

LANDE, Carl. 1977. «Introduction. The dyadic basis of clientelism». In Schmidt \& Steffen (orgs.) Friends, followers and factions: a reader. Berkeley: University of California Press.

LANNA, Marcos P.D. 1995. A Dívida Divina: troca e patronagem no nordeste brasileiro. Campinas: Editora da Unicamp. LEEDS, Anthony \& Leeds Elisabeth. 1977. A Sociologia do Brasil Urbano. Rio de J aneiro: Zahar.

LEÓN, Magdalena. 1993. “Trabajo Doméstico y Servicio Doméstico en Colombia”. In Elsa Chaney e Mary Garcia Castro (orgs.) Muchacha / cachifa / criada / empleada/ empregadinha / sirvienta y... más nada: trabajadoras domésticas en América Latina y Caribe. Venezuela: Ed. EPU.

MAUSS, Marcel. 1974. «Ensaio sobre a Dádiva: força e razão da troca nas sociedades arcaicas». In Sociologia e Antropologia. São Paulo: EPU/EDUSP.

MOTTA, Alda Brito da. 1977. Visão de mundo da empregada doméstica - um estudo de caso. Salvador: UFBA/Curso de Pós-Graduação em Ciências Humanas.

NOVAES, Regina. 1985. Os Escolhidos de Deus. Pentecostais, trabalhadores e cidadania. Rio de J aneiro: Editora Marco Zero.

NUNES LEAL, Victor. 1975. Coronelismo, enxada e voto. São Paulo: Alfa-Omega.

SAHLINS, Marshall. 1988. Cosmologias do Capitalismo: o Setor Trans-Pacífico do "Sistema Mundial". Conferência apresentada na XVI Reunião Brasileira de Antropologia. Campinas, 27 - 30 de março.

SARTI, Cynthia. 1989. "Reciprocidade e Hierarquia: relações de gênero na periferia de São Paulo". Cardernos de Pesquisa 70: 38-46.

1996. A Família como Espelho. Um estudo sobre a moral dos pobres. Campinas: Autores Associados.

1988. Mulher e família urbana: comentários sobre a bibliografia. Águas de São Pedro: XXII Encontro Anual da ANPOCS.

SCOTT, J ames. 1985. Weapons of the Near. Everyday forms of peasant resistance. Newttavem: Yale University Press. .1990. Domination and the arts of resistence: hidden transcripts. New Haven: Yale University Press.

SEGATO, Rita Laura. 1995. “Cidadania: Por que não? Estado e sociedade no Brasil à luz de um discurso religioso afrobrasleiro". In Dados - Revista de Ciências Sociais 38(3): 581-601.

THOMPSON, E. P. 1979. Tradicion, revuelta y consciencia de clase. Barcelona: Grijalbo. . 1987. Senhores e caçadores: a origem da lei negra. Rio de J aneiro: Paz e Terra.

. 1998. Costumes em comum: estudos sobre a cultura popular tradicional. São Paulo: Companhia das Letras.

VELHO, Otávio. 1995. Besta-Fera. Recriação do mundo. Rio de J aneiro: Relume-Dumará. 
J urema Brites

RESUMO

Em um estudo etnográfico acerca do serviço doméstico, estudei elementos, aparentemente paradoxais, que dão sustentabilidade às relações da maior categoria ocupacional feminina no Brasil. Uma das questões que meu trabalho levantou foi o descompasso entre as análises acadêmicas e as perspectivas das empregadas domésticas quanto às relações de trabalho e a perspectiva política decorrente de tais leituras. As empregadas encontravam vantagens no serviço doméstico, inexistentes no mercado de trabalho formal. Estas coincidiam justamente com aqueles fatores que os pesquisadores da condição feminina consideram como as raízes da subordinação que o serviço doméstico acarreta: relações personalistas e clientelistas estruturadas na organização da família patriarcal. Procurando uma perspectiva, onde o ponto de vista das pessoas investigadas exista como plausibilidade lógica, busquei compreender como as relações clientelistas se reproduzem neste campo de forma mais adequada que as promessas aportadas pela democracia cidadã.

\section{ABSTRACT}

In an ethnographic study on domestic workers (household maids), I studied several apparently paradoxical elements which underlie relationships involved in Brazil's major female occupation. One important question which emerged from my research is the divergence between, on the one hand, most academic analyses and, on the other, domestic workers' expectations as well as their political perspectives with regard to their work relations. The domestic workers found in their form of work advantages and bargaining space they did not encounter in the formal job market. Curiously, these advantages coincided to a great extent with those elements which feminist researchers generally point to when decrying the subordinate status of female domestic workers: personalistic and clientelistic relations embedded in the patriarchal family. Seeking to reveal the logical plausibility of my interviewees' opinions, I propose to explore how, in this field, clientelistic relations are more readily accepted than the promises proffered by the democratic state to its citizens. 